endocarditis following dental procedures: 1943 to 1993. J Oral Maxillofac Surg 1993; 51: 616-23.

2 Durack DT. Prevention of infective endocarditis. N Engl J Med 1995; 332: 38-44.

3 Crawford JS. Experiences with epidural blood patch. Anaesthesia 1980; 35: 513-5.

4 Berger CW, Crosby ET, Grodecki W. North American survey of the management of dural puncture occurring during labour epidural analgesia. Can J Anaesth 1998; 45: 110-4.

\section{High Frequency ventilation}

To the Editor:

I read with great interest the recent article of Aubin $e t$ al. describing the use of high frequency ventilation during the intraoperative care of an infant with diffuse bullous lesions. ${ }^{1}$ The authors should be congratulated for the care they provided this child. They demonstrated the overlap of the intensive care unit and the operating room as well as the need for anesthesiologists to maintain a working knowledge of new technology in both settings. In their discussion, the authors rightly state that $\mathrm{P}_{\mathrm{ET}} \mathrm{CO}_{2}$ cannot be measured during high frequency ventilation. ${ }^{2}$ Although the authors state that arterial blood gases must be sampled to frequently, I would like to suggest another alternative. We published our experience with transcutaneous $\mathrm{CO}_{2}$ monitoring during respiratory failure and following cardiothoracic surgery in infants and children. ${ }^{3,4}$ In addition to the obvious problems with $\mathrm{P}_{\mathrm{ET}} \mathrm{CO}_{2}$ monitoring during high frequency ventilation, other factors including ventilation-perfusion inequalities, sampling errors, and patient positioning can interfere with its accuracy. In infants and children with respiratory failure, we found that transcutaneous monitoring provided a better estimation of $\mathrm{PaCO}_{2} \cdot{ }^{3}$ Despite our success with this technology, its use outside the neonatal period and especially in the operating room remains limited. with recent advancements in the technology, transcutaneous $\mathrm{CO}_{2}$ has become a simple, non-invasive way of estimating $\mathrm{PaCO}_{2}$. We are currently investigating the applications of this technology in the adult population.

Joseph D. Tobias MD

Columbia, Missouri, USA

\section{References}

1 Aubin P, Vischoff D, Haig M, et al. Management of an infant with diffuse bullous pulmonary lesions using high-frequency oscillatory ventilation. Can J Anesth 1999; 46: 970-4.

2 Clark RH. High frequency ventilation. J Pediatr 1994; 124: 661-70.

3 Tobias JD, Meyer DJ. Non-invasive monitoring of carbon dioxide during respiratory failure in toddlers and infants: end-tidal versus transcutaneous carbon dioxide. Anesth Analg 1997; 85: 55-8.

4 Tobias JD, Wilson WR Jr, Meyer DJ. Transcutaneous monitoring of carbon dioxide tension after cardiothoracic surgery in infants and children. Anesth Analg 1999; 88: 531-4.

REPLY:

We agree with $\mathrm{Dr}$ Tobias that the measurement of $\mathrm{P}_{\mathrm{ET}} \mathrm{CO}_{2}$ is a poor way to estimate $\mathrm{PaCO}_{2}$ especially when using non-conventional modes of ventilation. Our experience with the measurement of carbon dioxide through a transcutaneous electrode in the operating room (OR) is limited. We are however accustomed to its routine use in the neonatal intensive care unit.

The reason why we do not use it in the OR is the lack of expertise and appropriate training of personnel working in the OR or in the pediatric intensive care unit (PICU). Although Dr. Tobias' articles validated this technique for even older patients than the neonates, they also show that technical variables (air bubbles, calibration, damaged material) and patient problems (skin thickness, edema) can alter the measures. These problems and a drift with time of the values obtained by the transcutaneous $\mathrm{CO}_{2}$ electrode explain why this promising technique has not yet gained wide acceptance among those of us involved in the PICU. Moreover, it is not always possible in the OR to change the monitoring site regularly to avoid thermal injuries. Therefore we continue to routinely insert arterial lines for sampling because we rely on the accuracy of the values obtained. Nevertheless, we agree that transcutaneous $\mathrm{CO}_{2}$ monitoring can be a useful compliment to other techniques especially when these are invasive or partly accurate.

We look forward to the development of alternative non invasive techniques to monitor our patients better and we agree that use of transcutaneous probes can be a promising avenue when the initial technical and practical problems are solved.

D. Vischoff MD

Montréal, Québec 